\title{
An interventional study with health education to modify the risk factors for the control of blood pressure among the newly diagnosed adult hypertensives, Andhra Pradesh
}

\author{
Sankar Deekala R. ${ }^{1}$, Hussain R A. ${ }^{2 *}$, Prabhu G R. ${ }^{3}$ \\ DOI: https://doi.org/10.17511/ijphr.2018.i1.02
}

1 Ravi Sankar Deekala, Assistant Professor, Department of Community Medicine, SVIMS, Sri Padmavathi Medical College for Women, Tirupati, Andhra Pradesh, India.

2* Altaf Hussain R, Associate Professor, Department of Community Medicine, SVIMS, Sri Padmavathi Medical College for Women, Tirupati, Andhra Pradesh, India.

3 Ravi Prabhu G, Professor \& Head, Department of Community Medicine, ACSR Government Medical College, Nellore, Andhra Pradesh, India.

Background: India is developing rapidly, which is evidenced by its developmental indicators. The country is in transitional period between developing and developed nations. With the effect of globalization, the lifestyleof the people also changed rapidly from traditional way of living to western style of living, which is contributing to rapid changes in disease patterns. Objective: To study the effect of health education intervention ondiet, lifestyle factors and thereby decrease in blood pressure levels among newly diagnosed adult hypertensive subjects. Methodology: A total of 60 newly diagnosed adult hypertensive subjects were selected randomly from a recent study done among the adults of both sex living in urban slum areas of Tirupati, Andhra Pradesh for this interventional study. Out of these, 30 subjects each were randomly allocated to the study and control groups. Results- In the study group, after health education intervention the proportion of hypertension decreased from $100 \%$ to $60 \%$ while in the controls, where health education was not given, it decreased from $100 \%$ to $90 \%$ only. Conclusion: There has been significant difference in the reduction of hypertension in the study group compared to control group. There has been reduction in all the risk factors studied after the intervention compared to the pre-intervention levels in the study group but however the differences were statistically significant with regard to extra salt intake, saturated fat intake and adequate fiber intake.

Keywords: Hypertension, Risk factors, Health education

\section{Corresponding Author}

Altaf Hussain R, Associate Professor, Department of Community Medicine, SVIMS, Sri Padmavathi Medical College for Women, Tirupati, Andhra Pradesh, India. Email: ravisankarsvmc@gmail.com
How to Cite this Article

Deekala Rs, Hussain RA, Prabhu GR. An interventional study with health education to modify the risk factors for the control of blood pressure among the newly diagnosed adult hypertensives, Andhra Pradesh. Public Health Rev Int J Public Health Res. 2018;5(1):8-15.

Available From

https://publichealth.medresearch.in/index.php/ijphr/ article/view/76
Manuscript Received 2018-01-17

Conflict of Interest No 2018-02-27

Funding

Review Round 2
2018-02-04
Ethical Approval
Yes

Review Round 3

Plagiarism X-checker $5 \%$
To Browse

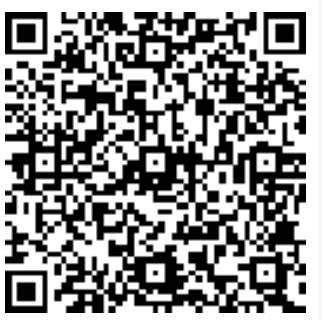

(C) 2018 by Ravi Sankar Deekala, Altaf Hussain R, Ravi Prabhu G and Published by Siddharth Health Research and Social Welfare Society. This is an Open Access article licensed under a Creative Commons Attribution 4.0 International License https://creativecommons.org/licenses/by/4.0/ unported [CC BY 4.0]. 


\section{Introduction}

Hypertension is an important non-communicable disease and increasing globally due to changing life styles. Being asymptomatic, it remains undetectable for a long time.

The disease is well amenable for control if detected in early stages with life style modification along with drug treatment. Subjects with hypertension are known to have two-fold higher risk of developing coronary artery disease, four times risk of congestive heart failure and seven times higher risk of stroke compared to normotensive subjects of developing countries is showing similar prevalence to that of developed countries $[2,3]$.

Hypertension while causing cerebrovascular attack is often associated with other co-morbid risk factors such as diabetes, hyperlipidemia and obesity which are dealt inade-quately resulting in high morbidity and mortality [4].

The role of modifiable risk factors of hypertension has been well documented in several studies especially the role of reduced salt and fat intake, restriction of alcohol intake, avoidance of sedentary life style and promoting regular physical exercise in the form of walking, outdoor games.

Although the effects of interventions to modify one or more of these risk factors have been documented in previous studies, the impact of the simple dietary changes and feasible life style factor modifications have not been carried out especially in this region.

Hence, this present study was conducted to delineate the impact of health education ondiet and lifestyle factors in the control of blood pressure among newly diagnosed adult hypertensives [1]. Urban population of developing countries is showing similar prevalence to that of developed countries $[2,3]$.

Hypertension while causing cerebrovascular attack is often associated with other co-morbid risk factors such as diabetes, hyperlipidemia and obesity which are dealt inade-quately resulting in high morbidity and mortality [4].

The role of modifiable risk factors of hypertension has been well documented in several studies especially the role of reduced salt and fat intake, restriction of alcohol intake, avoidance of sedentary life style and promoting regular physical exercise in the form of walking, outdoor games.
Although the effects of interventions to modify one or more of these risk factors have been documented in previous studies, the impact of the simple dietary changes and feasible life style factor modifications have not been carried out especially in this region.

Hence, this present study was conducted to delineate the impact of health education ondiet and lifestyle factors in the control of blood pressure among newly diagnosed adult hypertensives.

\section{Objective}

To study the influence of health education in modification of diet and lifestyle factors and there by reduction of blood pressure among newly diagnosed adult hypertensive subjects.

\section{Methodology}

Place of study: Urban slums of Nehru Nagar Urban Health Centre, a field practice area attached to S.V. Medical College, Tirupati, Andhra Pradesh.

Type of study: Interventional Study- (Randomized Controlled study) using health education interventional measure son modification of diet and lifestyle factors to control hypertension among the newly diagnosed adult hypertensive subjects found from the previous prevalence study.

Inclusion criteria: Newly diagnosed males and females aged more than 30 years and less than 50 years and People who had lived in the study area for more than 6 months before conducting the study were included in the study.

Exclusion criteria: Agelessthan 30 years and above 50 years, Pregnant women, those subjects with severe hypertension (Systolic Blood Pressure of $\geq 180 \mathrm{~mm} \mathrm{Hg}$ and/or Diastolic Blood pressure of $\geq$ $100 \mathrm{~mm} \mathrm{Hg}$ ), those who were already under anti hypertensive treatment and those who were not willing to participate were excluded from the study.

Ethical clearance was accorded by Institutional ethics committee, S. V. Medical College, Tirupati.

Sampling methods: The sample size for interventional study was calculated by fixing the alpha error of 0.05 and beta error of 0.10 giving a power of $90 \%$ assuming a combined standard deviation of $10 \mathrm{~mm} \mathrm{Hg}$ and mean difference of systolic blood pressure of $6 \mathrm{~mm} \mathrm{Hg}$ reduction as being significant between the intervention and nonintervention group. 
$\mathrm{N}=\{(Z \dot{a}+Z \beta) 2 \times \mathrm{S} 2\} / \mathrm{D} 2$ where $\mathrm{Z} \dot{\mathrm{a}}=1.96 ; Z \beta=$ 1.28; $S=$ Combined Standard deviation $=10 \mathrm{~mm}$ $\mathrm{Hg}, \mathrm{D}=6 \mathrm{~mm} \mathrm{Hg}$. By substituting the values, we get 29.19 (or) 30 subjects for each group.

Sample collection: A total of 60 out of 212 newly diagnosed adult hypertensive subjects from a prevalence study were taken randomly for the interventional study. Out of these, 30 subjects each were randomly allocated into the study and control groups. Equal number of males and females were included in each group to avoid gender bias.

Study Methods: A pre-tested interview schedule incorporating all demographic and life style factors including previous cardiac events, family history, smoking, alcohol intake, dietary pattern and exercise etc., was used for collecting the required information from the subjects.

Height was measured by using stadiometer. Weight was measured with calibrated weighting machine. BMI was calculated by using the Quetlet's index formula: weight $(\mathrm{kg}) /$ height $(\mathrm{m} 2)$. Classification recommended by WHO was used to define the obesity. Waist was measured using a properly calibrated tailor measuring tape and one layer of cloth was permitted while measuring waist for the females.

JNC VII criteria was used to classify hypertension [5]. Measurement of blood pressure was carried out on each participant by using the standard technique [6]. B.G. Prasad's socio economic status scale was used to classify study subjects based on per-capita monthly income $[7,8]$. The study subjects were explained the purpose of the study and informed consent was taken from the subjects. As this study is purely educative in nature, no drug intervention is included.

The study group was contacted every month for a period of 3 months for explaining the role of diet and life style factor modifications using standard health education material prepared by department of Community Medicine, Tirupati. For the next 3 months of follow up, the changes in the diet and life style factors among study subjects was assessed by monthly visits along with measurement of anthropometry like BMI, Waist Circumference and blood pressure during these visits. Similar visits at the same frequency were made to the control group subjects but no intervention (health education) was given except for recording down of data on modifiable risk factors, certain anthropometric data and blood pressure.
At the end of the six months, specific medical advice was given based on the review of the data from each subject including referral to a specialist for further follow up and treatment.

Statistical methods: The data were analyzed by using MS excel and Epi-info 3.5.1 version software. Descriptive statistics like Frequencies, means and standard deviations for the participant's characteristics and risk factors of hypertension were calculated.

Analytical statistics like Chi square test or Fischer's exact tests was used for discrete data and Student's $t$ test was used to examine the significant differences in the mean participant's characteristics between study and control groups.

A $p$ value of $<0.05$ and $<0.001$ was considered as significant and highly significant respectively.

\section{Results}

Based on the consideration of the limitation of logistics including time and moreover based on the minimum sample size required for statistical analysis, 30 subjects in each group (study and control) were chosen for the Interventional study on the role of Health Education in lowering blood pressure and modification of certain risk factors.

Table-1: Baseline data of Study and Control Groups (before Intervention).

\begin{tabular}{|l|l|l|l|l|}
\hline S.No & \multicolumn{1}{|c|}{ Variable } & Study Group & \multicolumn{1}{|c|}{$\begin{array}{c}\text { Control } \\
\text { group }\end{array}$} & \multicolumn{1}{c|}{$\begin{array}{c}\text { P } \\
\text { value }\end{array}$} \\
\hline 1 & Age (Mean \pm SD) & $41.5 \pm 4.8$ & $42.0 \pm 4.7$ & $\begin{array}{l}0.64 ; \\
\text { NS }\end{array}$ \\
\hline 2 & Sex & $15(50.0)$ & $15(50.0)$ & $1.00 ;$ \\
\cline { 2 - 6 } & (a) Male (\%) & $15(50.0)$ & $15(50.0)$ & NS \\
\cline { 2 - 6 } & (b) Female (\%) & $2059.1 \pm$ & $2312.5 \pm$ & $0.43 ;$ \\
\hline 3 & $\begin{array}{l}\text { Percapita Monthly Income } \\
\text { (Mean } \pm \text { SD) }\end{array}$ & 1288.2 & 1199.2 & NS \\
\hline
\end{tabular}

The mean age, per-capita monthly income and sex distribution was similar in study and control groups. Thus the study and control groups were comparable with regard to these variables.

Table-2: Prevalence of Certain Modifiable Risk factors between Study and Control Groups (before Intervention) ( $N=30$ each for Study and Control)

\begin{tabular}{|l|l|l|l|l|}
\hline S.No & Variable & $\begin{array}{c}\text { Study Group Number } \\
(\%)\end{array}$ & $\begin{array}{r}\text { Control Group Number } \\
(\%)\end{array}$ & $\begin{array}{c}\mathbf{P} \\
\text { value }\end{array}$ \\
\hline 1 & Smoking & $6(20.0)$ & $4(13.3)$ & $\begin{array}{l}0.48 ; \\
\text { NS }\end{array}$ \\
\hline
\end{tabular}




\begin{tabular}{|l|l|l|l|l|}
\hline 2 & Alcohol intake & $5(16.7)$ & $11(36.7)$ & $0.08 ; \mathrm{NS}$ \\
\hline 3 & Extra salt consumption & $24(80.0)$ & $27(90.0)$ & $0.27 ; \mathrm{NS}$ \\
\hline 4 & No Exercise & $21(70.0)$ & $26(86.7)$ & $0.11 ; \mathrm{NS}$ \\
\hline 5 & Saturated Fat intake & $27(90.0)$ & $24(80.0)$ & $0.27 ; \mathrm{NS}$ \\
\hline 6 & Inadequate Fiber diet & $18(60.0)$ & $16(53.3)$ & $0.60 ; \mathrm{NS}$ \\
\hline 7 & Overweight/Obesity (BMI) & $21(70.0)$ & $16(53.33)$ & $0.39 ; \mathrm{NS}$ \\
\hline 8 & $\begin{array}{l}\text { Central Obesity (Waist } \\
\text { Circumference) }\end{array}$ & $12(40.0)$ & $11(36.7)$ & $0.79 ; \mathrm{NS}$ \\
\hline 9 & Hypertension (JNC VII) & $30(100.0)$ & $30(100.0)$ & $1.00 ; \mathrm{NS}$ \\
\hline
\end{tabular}

The proportion of various risk factors like smoking, alcohol intake, extra salt intake, lack of exercise, saturated fat intake and inadequate fiber intake, overweight/obesity, central obesity \& the prevalence of hypertension was similar in study and control groups.

Thus, the study and control groups were comparable with regard to these risk factors and the results after the intervention are valid in their inference.

Table-3: Number Hypertensives among Study and Control Groups during the follow up ( $\mathbf{N}=\mathbf{3 0}$ each for Study and Control).

\begin{tabular}{|l|l|l|l|}
\hline S.No & \multicolumn{1}{|c|}{ Time of study } & Study Group (\%) & Control group (\%) \\
\hline 1 & Pre-intervention & $30(100.0)$ & $30(100.0)$ \\
\hline 2 & First follow up visit & $30(100.0)$ & $30(100.0)$ \\
\hline 3 & Second follow up visit & $24(80.0)$ & $30(100.0)$ \\
\hline 4 & Third follow up visit & $18(60.0)$ & $27(90.0)$ \\
\hline
\end{tabular}

In the study group, the percentage of hypertensives decreased from $100.0 \%$ to $60.0 \%$ while in the controls, it decreased from $100.0 \%$ to $90.0 \%$ only.

Table-4: The changes in the risk factors in the study group before and after intervention $(\mathbf{N}=\mathbf{3 0})$.

\begin{tabular}{|l|l|l|l|l|}
\hline S.No & \multicolumn{1}{|c|}{ Variable } & \multicolumn{1}{|c|}{ Before (\%) } & After (\%) & \multicolumn{1}{c|}{ P value } \\
\hline 1 & Smoking & $6(20.0)$ & $4(13.3)$ & $0.48 ;$ NS \\
\hline 2 & Alcohol intake & $5(16.7)$ & $3(10.0)$ & $0.70 ;$ NS \\
\hline 3 & Extra salt intake & $24(80.0)$ & $6(20.0)$ & $<0.001 ; \mathrm{S}$ \\
\hline 4 & Exercise & $9(30.0)$ & $14(46.7)$ & $0.18 ; \mathrm{NS}$ \\
\hline 5 & Saturated fat intake & $27(90.0)$ & $6(20.0)$ & $<0.001 ; \mathrm{S}$ \\
\hline 6 & Adequate fiber intake & $12(40.0)$ & $24(80.0)$ & $<0.001 ; \mathrm{S}$ \\
\hline 7 & Overweight/Obesity & $21(70.0)$ & $20(69.1)$ & $0.77 ; \mathrm{NS}$ \\
\hline 8 & Central obesity & $12(40.0)$ & $11(36.7)$ & $0.77 ; \mathrm{NS}$ \\
\hline
\end{tabular}

There has been reduction in all the risk factors studied after the intervention compared to the preintervention levels in the study group but the differences were statistically significant with regard to extra salt intake, saturated fat intake and adequate fiber intake.
Table-5: The changes in the risk factors in the control group before and after intervention $(\mathbf{N}=\mathbf{3 0})$

\begin{tabular}{|l|l|l|l|l|}
\hline S.No & \multicolumn{1}{|c|}{ Variable } & \multicolumn{1}{|c|}{ Before (\%) } & \multicolumn{1}{|c|}{ After (\%) } & \multicolumn{1}{c|}{ P value } \\
\hline 1 & Smoking & $4(13.3)$ & $4(13.3)$ & $1.00 ; \mathrm{NS}$ \\
\hline 2 & Alcohol intake & $11(36.7)$ & $11(36.7)$ & $1.00 ; \mathrm{NS}$ \\
\hline 3 & Extra salt intake & $27(90.0)$ & $25(83.3)$ & $0.44 ; \mathrm{NS}$ \\
\hline 4 & Exercise & $4(13.3)$ & $4(13.3)$ & $1.00 ; \mathrm{NS}$ \\
\hline 5 & Saturated fat intake & $24(80.0)$ & $19(63.3)$ & $0.15 ; \mathrm{NS}$ \\
\hline 6 & Adequate fiber intake & $14(46.7)$ & $18(60.0)$ & $0.30 ; \mathrm{NS}$ \\
\hline 7 & Overweight/Obesity & $16(53.3)$ & $17(56.7)$ & $0.60 ; \mathrm{NS}$ \\
\hline 8 & Central obesity & $11(36.7)$ & $11(36.7)$ & $1.00 ; \mathrm{NS}$ \\
\hline
\end{tabular}

The prevalence of various risk factors more or less remained same during the follow up in the control group.

Table-6: Reduction in risk factor levels \& Hypertension between study and control groups before and after intervention

\begin{tabular}{|c|c|c|c|c|}
\hline S.No & Variable & $\begin{array}{l}\text { Study } \\
\text { Group }\end{array}$ & $\begin{array}{l}\text { Control } \\
\text { Group }\end{array}$ & P value \\
\hline 1 & Smoking reduction & $2 / 6(33.3)$ & $0 / 4(0.0)$ & $0.51 ; \mathrm{NS}$ \\
\hline 2 & Alcohol reduction & $2 / 5(40.0)$ & $0 / 11(0.0)$ & $0.44 ;$ NS \\
\hline 3 & Extra salt reduction & $\begin{array}{l}18 / 24 \\
(75.0)\end{array}$ & $2 / 27(7.4)$ & $\begin{array}{l}<0.001 ; \\
\mathrm{S}\end{array}$ \\
\hline 4 & Exercise improvement & $5 / 14(35.7)$ & $0 / 4(0.0)$ & $0.27 ; \mathrm{NS}$ \\
\hline 5 & $\begin{array}{l}\text { Saturated fat intake } \\
\text { reduction }\end{array}$ & $21 / 27(77.8)$ & $5 / 24(20.8)$ & $\begin{array}{l}<0.001 ; \\
\mathrm{S}\end{array}$ \\
\hline 6 & Fiber diet improvement & $12 / 24(50.0)$ & $4 / 18(22.2)$ & $0.04 ; \mathrm{S}$ \\
\hline 7 & Overweight/Obesity & $1 / 21(4.8)$ & $0 / 16(0.0)$ & $1.00 ; \mathrm{NS}$ \\
\hline 8 & Central obesity & $1 / 12(8.3)$ & $0 / 11(0.0)$ & $0.44 ;$ NS \\
\hline 9 & Hypertension reduction & $12 / 30(40.0)$ & $3 / 30(10.0)$ & $0.007 ; \mathrm{S}$ \\
\hline
\end{tabular}

There has been reduction in all the risk factors studied after intervention in study group compared to control group but statistical significance was found with regard to extra salt reduction, saturated fat intake and fiber diet improvement only.

There has been significant difference in the reduction of hypertension in the study group compared to control group.

\section{Discussion}

For this Interventional study, 60 recently diagnosed hypertensives (most of them stage 1 ) were selected and randomly allocated into study and control groups. The baseline parameters like age, sex, percapita monthly income and various risk factors (smoking, alcohol, extra salt, no exercise, saturated fat intake, inadequate dietary fiber, mean BMI, systolic and diastolic blood pressures, over weight / 
Obesity, central obesity) was similar between study and control group so that the results of intervention are valid.

It was found in the present study that the educational intervention was effective in reducing the prevalence of various risk factors in the study group in comparison to the control group. The smoking decreased from $20.0 \%$ to $13.3 \%$; alcohol from $16.7 \%$ to $10.0 \%$; additional salt from $80.0 \%$ to $20.0 \%$; saturated fat from $90.0 \%$ to $20.0 \%$; adequate dietary fiber consumption improved from $40.0 \%$ to $80 \%$ while those doing physical exercise improved from $30.0 \%$ to $46.7 \%$.

The control group more or less remained same after follow up visits without intervention compared to before follow up visits without intervention.

Thus, in the study group, the prevalence of all knownrisk factors decreased. Statistical analysis of the results by comparison to the control group had revealed that the differences were significant with regard to extra salt intake, saturated fat intake and adequate fiber intake.

The most significant finding is that the prevalence of hypertension decreased from $100 \%$ to $60 \%$ being statistically significant compared to the control group.

The mean systolic as well as diastolic blood pressure levels decreased (mean reduction of $6.6 \mathrm{~mm} \mathrm{Hg}$ systolic and $4.2 \mathrm{~mm} \mathrm{Hg}$ diastolic pressure) significantly in the study group compared to the control group.

Similar finding of benefitfrom walking, salt reduction and yoga was found in urban Pondicherrywhere it was found that the reduction was found to be $5.3 / 6.0,2.6 / 3.7$ and $2.0 / 2.6 \mathrm{~mm} \mathrm{Hg}$ in the three groups respectively [9].

In another study in urban Pondicherrysimilar findings were noted [10]. The Mumbai studyalso found significant reduction in the mean systolic and diastolic blood pressure levels after health education intervention [11].

In a South India study, after 10 weeks of intervention, systolic blood pressure decreased by $1.56 \mathrm{~mm} \mathrm{Hg}(P=0.000)$ and diastolic blood pressure decreased by $0.74 \mathrm{~mm} \mathrm{Hg}(P=0.000)$ [12]. Thus, non-pharmacological interventions are best during the early stage of hypertension management.
This is in concurrence with findings as reported in a review [13]. Several RCTs in western countries also found mean reduction in systolic and diastolic blood pressure to be 3.4 and $2.4 \mathrm{~mm} \mathrm{Hg}$ respectively [14].

Meta-analysis of a few RCTs abroad found overweight to have the strongest effect on blood pressure reduction by around $5 \mathrm{~mm} \mathrm{Hg}$ systolic and $3 \mathrm{~mm} \mathrm{Hg}$ diastolic blood pressure [15].

Another review has found the population attributable risk reduction of hypertension to be 11$25 \%$ with overweight, 5-13\% with physical activity and $9-17 \%$ with reduction of salt intake and least with alcohol reduction (2-3\%) [15].

Similar review in western countries of several RCTs (with a minimum duration of 6 months) revealed low salt intake to reduce systolic pressure by 1.1 $\mathrm{mm} \mathrm{Hg}$ and diastolic pressure by $0.6 \mathrm{~mm} \mathrm{Hg}$.

In a study in Canada, it was found that life style modification by reduction of body weight, regular exercise, reduction in salt intake and stress management reduces the hypertension [16].

In Singapore also, the National Healthy life style programme significantly decreased smoking, improved exercise among the communities with resultant reductions in hypertension [17].

A meta-analysis of several RCTs done in western countries during 1966-1995 also found net reduction of prevalence of several risk factors for hypertension like salt restriction $-2.9 \%$, weight loss - 5.2\%, stress control $-1 \%$ and exercise - $0.8 \%$ [18].

Another review also concluded that reduced salt intake, weight loss, moderation of alcohol and dietary modifications like DASH (Dietary Approaches to Stop Hypertension) can reduce the prevalence of hypertension significantly [19].

A study in Europe found aerobic exercise to reduce the systolic pressure by $5 \mathrm{~mm} \mathrm{Hg}$ and diastolic pressure by $4 \mathrm{~mm} \mathrm{Hg}$. It also found that DASH diet, salt reduction and alcohol reduction significantly reduce the prevalence of hypertension [20]. Similar reductions were reported in other studies in western countries $[21,22]$.

The mean BMI levels, obesity prevalence and mean waist circumference levels have been similar in the study and control group even after intervention. 
This can be easily explained by the known fact that the weight reduction takes place rather slowly and may require up to 6 months time while the blood pressure levels and behavioral risk factors require less time.

The Mumbai study has found the mean weight as well as BMI to be significantly reduced after 1 year of intervention [11]. The study in South Indiato decrease the mean body weight by $0.17 \mathrm{~kg}$ and prevalence of hypertension from $7.8 \%$ to $4.5 \%$ after intervention [12]. Thus the results of the present intervention study support the findings by several studies in India and abroad that the nonpharmacological interventions like health education on the reduction of the risk factors identified namely weight reduction, regular physical exercise, modification of diet (DASH diet), salt reduction and reduction in behavioral factors like smoking and alcohol can be effective strategies for early management of hypertension and can delay the institution of antihypertensive drug therapy.

\section{Conclusions}

The present study found that there has been significant difference in the reduction of hypertension in the study group compared to control group. There has been reduction in all the risk factors studied after the intervention compared to the pre-intervention levels in the study group but the differences were statistically significant with regard to extra salt intake, saturated fat intake and adequate fiber intake.

\section{Recommendations}

01. Regular screening programmes should be conducted for early identification of hypertension. At the same time, blood pressure should be routinely measured for all adult patients (aged 30 and above) attending government or private institutions including hospitals, health centres, clinics and nursing homes.

02. The health education intervention in this study has demonstrated its effect in the reduction of several risk factors like smoking, alcohol, additional salt intake, saturated fat intake, dietary fiber intake and lack of physical exercise. Hence, health education is effective in controlling blood pressure by reducing its risk factors in those cases with stage I hypertension, which can delay the starting of antihypertensive drug therapy.

\section{Limitations}

01 . This present study could not assess some of the risk factors like diabetes, level of stress in individuals as it would become difficult in terms of limitation of time.

02. Similarly, no lab investigation could be conducted like blood sugar level, lipid profile at least in a sub sample due to the logistic considerations of cost and time.

03. The intervention was planned for duration of 3 months only due to the logistic problems like cost, time and other resource problems.An intervention for a longer period might have given more reliable and useful findings.

04. The sample for the interventional study could be higher for more reliable results on the effect of intervention.

05. The reduction achieved among the study group in the interventional study might not be sustained for a longer period as motivation is required for continued adoption of the changed life style patterns.

\section{Author contributions}

01. Dr. Ravi Sankar Deekala: Study designing, protocol preparation, Institutional Ethics Committee approval, Data collection, Data entry, Data analysis \& manuscript preparation.

02. Dr. Altaf Hussain R: Study designing, protocol preparation \& manuscript preparation.

03. Dr Ravi Prabhu G: Study designing, protocol preparation, Data analysis.

\section{What this study Adds}

This study suggests to health planners to take remedial measures to address growing hypertension in the community and thereby prevention of its complications, through low cost \& effective health education intervention measures like lifestyle changes, dietary modification etc.

\section{Reference}

01. Mohan V, Deepa M, Farooq S, Datta M, Deepa R. Prevalence, awareness and control of hypertension in Chennai-The Chennai Urban Rural Epidemiology Study (CURES-52). J Assoc Physicians India. 2007 May;55;326-32.

[Crossref] 
02. Vorster $\mathrm{HH}$. The emergence of cardiovascular disease during urbanisation of Africans. Public Health Nutr. 2002 Feb;5(1A)239-43.

[Crossref]

03. Khor GL. Cardiovascular epidemiology in the Asia-Pacific region. Asia Pac J ClinNutr. 2001;10(2)76-80.

[Crossref]

04. GodleyP, Pham H, RohackJ, WoodwardB, YokoyamaK, Maue SK. Opportunities for improving the quality of hypertension care in a managed care setting. AmJ Health Syst Pharm. $2001 ; 58(18) 1728-1733$.

[Crossref]

05. U S Department of Health and Human Services. The Seventh Report of the Joint National Committee on Prevention, Detection, Evaluation and Treatment of High Blood Pressure. NIH Publication. 2004;No-04-5230;11-12.

[Crossref]

06. Canadian Hypertension Education Program. CHEP Recommendations for the Management of Hyper-tension. 200;:1-39.

[Crossref]

07. Agarwal AK. Social Classification- The need to update in the present scenario. Indian J Community Med. 2008;33(1)50-51.

doi: 10.4103/0970-0218.39245 [Crossref]

08. Available from: http://eaindustry. nic. in/asp2/listd. asp (Cited on Sep 2010). [Crossref]

09. Saptharishi LG, Soudarssanane MB, Thiruselva kumar D, Navasakshi D, Mathanraj S, Karthigeyan M, Sahai A, et al. Community based Randomized Controlled Trial of non pharmacological interventions in prevention and control of hypertension among young adults. Indian J Community Med. 2009;34(4)329-34. doi: 10.4103/0970-0218.58393 [Crossref]

10. Hema Subramaniyan, Bala Soudarssanane M, Jayalakshmy R, Thiruselva kumar D, Navasakshi D, Ajith Sabai, Saptharishi LG. Non pharmacological interventions in hypertensionA Community based Cross over Randomized Control Trial. Indian J Community Med. 2011;36(3)191-96.

doi: 10.4103/0970-0218.86519 [Crossref]
11. Hemanth Mahajan, Yasmeen Kazi, Bhuvan Sharma, Velhal GD. Health education- An effective intervention in hypertensive patients. International Journal of Recent Trends in Science and Technology. 2012;4(2)77-82. [Crossref]

12. Subitha Lakshminarayanan, Soudarssanane M, Bala, Murugesan Ramanujan, Kannan G. Effectiv eness of physical activity promotion in blood pre ssure and blood sugar reduction- A Community based intervention study in rural South India. J Family Community Med. 2012;19(2)81-7. doi: $10.4103 / 2230-8229.98284$ [Crossref]

13. Rajeev Gupta, Soneil Gupta. Strategies for initial management of hypertension. Indian J Med Res. 2010;132(5)531-42.

[Crossref]

14. Fagard RH. Effects of exercise, diet and their combination on blood pressure. J Hum Hypertens. 2005;19(3)20-24.

doi: 10.1038/sj.jhh.1001956 [Crossref]

15. Geleijnse JM, Grobbe DE, Kok FJ. Impact of dietary and life style factors on the prevalence of hypertension in western populations. Journal of human hypertension. 2005;19;S1-4.

[Crossref]

16. Campbell NR, Burgesse E, Choi BC, Taylor G, Wilson E, Cleroux J, Fodor JG, Leiter LA, Spence D. Life style modifications to prevent and control hypertension. CMAJ. 1999;160(9)7-12. [Crossref]

17. Jeffery Cutter, Bee Yian Tan, Suok Kai Chew. Levels of cardiovascular disease risk factors in Singapore following a national intervention programme. Bulletin of the World Health Organization. 2001;79(10)908-15.

[Crossref]

18. Shah Ebrahim, George Davey Smith. Lowering blood pressure- a systematic review of sustain ed effects of non pharmacological interventions. J Public Health Med. 1998;20(4)441-48. [Crossref]

19. Lawrence J Appel, Michael W Brands, Stephen R Daniels, Njeri Karanja, Patricia J Elmer, Frank M sacks, et al. Dietary Approaches to prevent and treat hypertension- A Scientific statement from the American Heart Association. VAMED CTR BOISE. 2012;296-308.

Available from: [Article] [Crossref] 
20. Jennifer Lochner, Bruin Rugge, Dolores Judkins. How effective are life style changes for controlling hypertension?. J Fam Pract. 2006;55(1)73-74.

[Crossref]

21. Aram V Chobanian, Martha Hill. National Heart, Lung and Blood Institute workshop on sodium and blood pressure. A critical review of current scientific evidence. 2000;35(4): 858-63.

Available from: [Article] [Crossref]

22. Randy Wexler, Glen Aukerman. Non pharmacologic strategies for managing hypertension. American Academy of Family Physicians. 2006;73(11)1953-56.

[Crossref] 